\title{
Working Relationships for Sustainability: Improving Work-Based Relationships in Local Government to bring about Sustainability Goals
}

\section{Commonwealth Journal of Local Governance Issue 10: December 2011- June 2012 http://epress.lib.uts.edu.au/ojs/index.php/cjlg}

\section{Jade Herriman \\ University of Technology, Sydney}
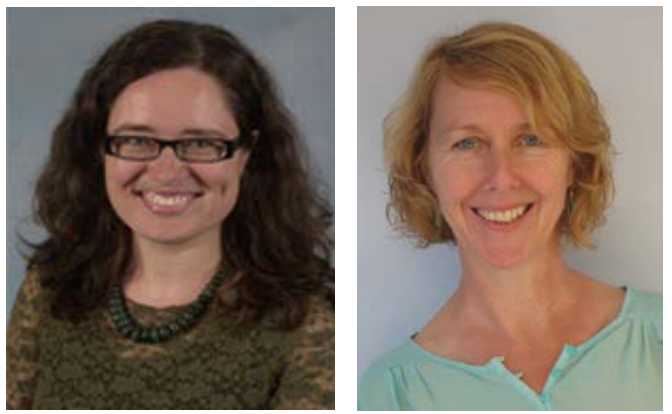

\section{Phil Smith \\ Know/Hands \\ Education Consultancy}

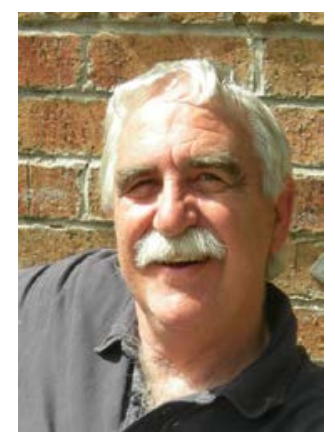

\section{Hazel Storey}

The Storey Agency

Pty Ltd

\section{Grahame Collier}

T Issues

Consultancy

\begin{abstract}
:
There's no escape: we are always in relationship. Being aware of this matters. Doing something to build constructive relationships for sustainability, matters even more.

This paper considers the connection between good relationships and effective sustainability work in local government. It draws on the collective experiences of four practitioners who have worked over many years in, with or for local government and argues that a good deal of project success is contingent upon the development of positive relationships with stakeholders, contractors, communities, businesses, colleagues, partners and other agencies and agency officers.
\end{abstract}

Relationships can help or hinder project process, progress and outcomes. This paper identifies some approaches for building quality relationships and uses examples to highlight these strategies. These include: recognising that developing and maintaining resilient relationships and high quality communication is a critical foundation for success; designing projects with explicit relationship outcomes; and allocating time, money and other resources to support the development of effective relationships. 


\section{Introduction}

Humans are tuned for relationships (Abram, 1997). Humans developed in relationship with everything around them over many thousands of years; we are who we are through our relationships with each other, organisations, systems and processes, events, experiences, other species, the inanimate elements of Earth, resources and ideas. We are always in relationship.

The authors share a strongly held view that sustainability ${ }^{33}$ is all about relationships. The social dimensions of a more sustainable future are about connections between people. And the environmental dimensions of sustainability require people to work together to make change (Cox, 1995 and Brown et al 2004).

This paper draws on the experience and perspectives of four practitioners who have worked on sustainability projects in state government, local government and tertiary institutions, and as project managers and consultants to local governments and other organisations; their work is primarily to do with environment, sustainability and community engagement.

The main purpose of this paper is to put the issue of relationships on the agenda for the sustainability sector and to explore questions related to the extent to which we value quality relationships in our work.

We propose that a focus on relationships needs to be at the core of thinking about sustainability, because relationships impact on behaviours. Since problems continue to emerge and evolve, so too must relationships. We argue that failing to invest in relationships can have tangible negative impacts on policy and implementation for sustainability (Rogers, 1970, p287).

This paper draws attention to some common situations where there may be structural and cultural barriers that prevent relationships being given due attention. We draw on theory to make sense of some of these experiences, and to suggest new ways that relationships can be valued in working towards sustainability.

\section{Why relationships are important for sustainability}

Local government plays, and must continue to play, an increasingly important role in helping local communities (householders, businesses, landowners, developers) respond to the challenges of sustainability (Wild, 2006). It is the level of government best placed to

\footnotetext{
${ }^{33}$ In this paper we use the word sustainability interchangeably with 'sustainable development', which reflects common use in Australia - see section 2 for details.
} 
appreciate and respond to local issues; it is the level best able to build, maintain and facilitate good relations in and across the community (NSW Division of Local Government, 2009). In taking on this role, local government is able to provide excellent models of sustainable practice in its own operations.

Capra (1982 p 290) suggests that sustainability is all about relationships and that a sustainable community is aware of the multiple relationships among its members. Nourishing the community means nourishing those relationships. Mutually enhancing relationships are important, said Thomas Berry (1998).

\section{What do we mean by sustainability?}

In this paper we use the term 'work for sustainability' to refer to work that is being undertaken to value and contribute to the objectives of sustainable development through supporting social, natural and cultural capital in an equitable way and to meet the needs of future generations.

By sustainability we mean addressing environmental issues to ensure that we maintain our 'natural capital' (including biodiversity) as well as our 'social capital' i.e. sustaining human populations into the future in a way that is equitable (inter and intra generational equity) and Maintaining quality of life (Brown 2004). This involves considering quadruple bottom lines ${ }^{34}$ in decision making, and regarding a healthy economy as only part of a healthy community.

Sustainability requires ongoing changes in how we think about situations ${ }^{35}$. It is a cyclic process of enquiry, decision making, action and reflection in the presence of information about values and impacts. Single projects, no matter how large, do not solve sustainability problems, only engaged people do. It is the thinking about and learning from the project by people that contribute to further positive change.

New ways of relating to resources and climate require new ways of seeing the world and our place in it. These kinds of changes may be easier to make and to motivate if we have access to peers and communities that are working towards sharing similar challenges and interests.

\footnotetext{
${ }^{34}$ Triple bottom line (TBL) provides a methodology for councils to report across three dimensions of performance; environmental, social and economic, and has been quite widely explored by the Australian local government sector (e.g.: Jigsaw Services, 2004). The 'quadruple bottom line' concept builds on this idea and includes four dimensions: environmental sustainability, economic or fiscal sustainability, social or community sustainability and civic leadership or corporate governance (see for example Liverpool City Council n.d.). Some councils have interpreted these four pillars to be environmental, economic, social and cultural (e.g.: City of Norwood, Payneham and St Peters 2012).

${ }^{35}$ Key concepts include: human wellbeing, quality of life; future generations, (intergenerational equity); equity within this generation (intra-generational equity); precautionary principle; conservation of biological diversity, equity and balance.
} 


\section{What kinds of relationship are we talking about?}

As practitioners working towards a more sustainable future we are working with and through our relationships - with community, with one another, with people in institutions. The vital relationships for success in achieving sustainability outcomes in projects are those between and amongst project staff and stakeholders including:

- Officers and managers from local, state, commonwealth agencies

- Contractors and other business personnel

- Not for Profit organisations

- Schools and other formal educational facilities

- Target audience for the project/s.

Each of these cases involves two or more people who share policy or programme objectives, and seek to achieve their ends through influencing the other through dialogue. Their training and experience may be in environmental science, policy development, strategic planning, activism, hands on environmental restoration practices, education programme design (or similar) and yet the means by which they are brought together is through a professional relationship. ${ }^{36}$

These relationships may be fleeting or ongoing; they may be defined through official roles; and yet may be unclear with respect to other parameters; they may be shrouded with hostility and mistrust; or perhaps there may be a sense of mutual interest in reaching favourable outcomes. Relationships - like projects and the issues they seek to address - are dynamic; they need to evolve accordingly.

This broad contextualisation of relationships reflects our deliberate attempt to embrace honestly and consider the wide range of relationships that exist in our professional spheres, and include this full suite within the bounds of our discussion.

Box 1 - Good relationships are important to sustainability outcomes because:

- Making substantial and ongoing social change often requires a willingness to ask questions and learn from others. This process is much easier within supportive relationships.

- At the end of the day, it is people who get things done (or who get in the way of getting things done). It is people together who bring passion, commitment and progress to challenging problems. Movement toward sustainable outcomes happens more effectively when people are pulling in the same direction.

- $\quad$ For sustainability outcomes to be met, we need to generate a shared understanding of situations and aspirations, and we can only do that through quality relationships. Without good

\footnotetext{
${ }^{36}$ At this juncture it should be noted that the situation is often more complex than the examples indicate. Often a number of relationships are being worked up at any one time and group relationships are as vital as one-on-one interactions
} 
relationships, we don't have good outcomes for everybody.

- Relationships help extend our boundaries of care. In relationship, we learn we are interdependent, more than our 'skin encapsulated ego' (Watt, 1957). Sustainability outcomes result from acknowledging and acting on that interdependence across all aspects of the quadruple bottom line. Outcomes themselves are not sustainable without ongoing relationships. Otherwise, we're making snapshots not a movie.

\section{Building relationships in sustainability initiatives - Whose responsibility is it?}

Within any sustainability initiative, the project manager has responsibilities in mediating, facilitating and supporting good relationships. But it is not just the project manager who holds these responsibilities: all project stakeholders need to ensure that good relationships are established and maintained. It is the project manager's responsibility to facilitate this conversation and understanding within the project community. Project managers can set expectations and offer guidance; they need to be aware that people are watching them for clues about how to behave in relationships with others. Establishing a healthy culture as part of the project community can help win the hearts and minds of clients, staff, passionate community members and elected officials (de Souza Briggs, 2003).

Relationships within a project are many and diverse, and they are the responsibility of all project participants. Sustainability requires understanding and action on the view that we have a relationship to everyone, everywhere, 'every when'. We do have to work to get the scale and nature of the relationship right. And it's important to remember that relationships don't just happen. They require attention and care. They need to be acts of creation every day.

\section{Do we value relationships in our work?}

Rhetoric about the importance of relationships abounds among those interested in sustainability in local government. It would be rare for someone working in this sector to talk down the value of high quality working relationships and how integral they are to achieving sustainable outcomes. But the truth is that relationships are not always valued, worked at, adequately funded and/or given sufficient time to develop and mature in many sustainability projects.

There are a number of reasons why relationships are undervalued and at times break down. They range from a lack of shared understanding about why relationships between people are crucial to the success of a sustainability project or programme, to the quest for quick and quantifiable sustainability outcomes at the expense of the human connections. Between these two extremes, relationship-building takes time and some see this as a waste of time, whilst 
others lack the communication skills and commitment that are essential for quality relationship building.

At times relationships are not built because people just don't get on, or they have very different life views and values. When this results in conflict rather than cohesion, it requires extra effort, and even mediation to enable people to work together to find common ground.

Unfortunately many examples exist where relationship building has not worked. ${ }^{37}$ The following snapshots are provided to illustrate some of the ways in which we undervalue relationship building:

- Two neighbouring Councils conduct a joint project to restore the riparian zone along a creek that crosses their local government areas. One of the Councils works constructively with its community to establish vegetation restoration groups along the creek and encourage a strong local commitment to place. The other Council does not actively support community action. Local residents are disenchanted by the lack of support they, and the project, receive.

- A Council continues to have high staff turnover at an officer level sustainability position. Each new staff member must 'learn from scratch' who the key players in the community are, and what the relationships are between each group and with each group and Council. Often more pressing matters like project deadlines and deliverables compete for time. Community members are frustrated that every time they get to know a staff member and have begun working fruitfully together, and shared their considerable local knowledge there is a new person to get to know.

- $\quad$ A State Government agency conducts a major consultation to seek the views of local government staff about a draft policy. Despite a number of promises to the contrary, the consultation document, which contained a summary and analysis of stakeholder views, is not made public to those involved in the process. This has significant impact on relationships between the agency and its local government partners.

Perhaps some of these examples resonate with your experience.

Another common scenario is when a grant-funded project employs a project manager working within a set timeframe for implementing a project. The project officer (or team)

\footnotetext{
${ }^{37}$ Note: These are hypothetical examples, informed by many and various actual situations over the past decade in countless councils. No one particular Council or community group is referred to; any similarities are purely coincidental.
} 
needs to work alongside people in the funding body, the Council staff and councillors, other agencies and with subcontractors/consultants and people in the community. Because grantfunded projects are time-limited, good relationships with all of these people can mean the difference between outstanding success and dismal failure. While a substantial amount of environmental focussed funding is directed in these projects towards 'on-ground' outcomes, we suggest that when these projects fall down it is in part because of poor relationship management.

Some of the literature in this field focuses on providing techniques for change management and skills required to build engagement (eg: DSE, 2005). It rarely talks in detail about the need to recognise the time and effort that is required to work on the relationships; to enable trusting relationships to be developed with new staff, existing staff, senior management and the community; nor to develop 'knowing' that is required as a precursor for willingness to share, change or adapt. It does not help people to map their relationships and plan them effectively and generally undervalues the need for high quality relationship building processes.

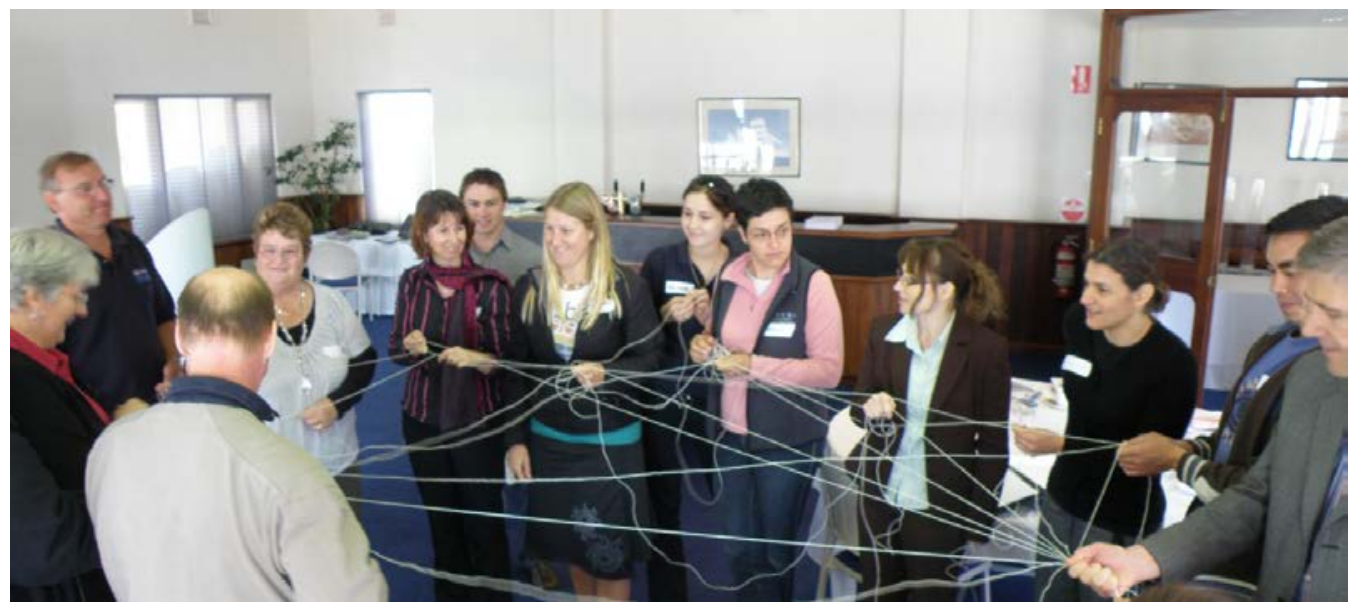

Workshop: Perth WA, 2008. Participants mapping relationships with other agencies Photograph: Grahame Collier

\section{Examples from local government practice - some different approaches}

The following three case studies represent different approaches to building relationships in sustainability. Readers will find some aspects of each case study of more interest than others, and some cases more directly applicable to their work than others. Each case study however, does provide a tangible example of what local governments are doing to improve, extend and validate relationships in project management and design and in the workplace. 


\section{Case Study 1: Relationships with community-Parramatta City Council Residents' Panel}

This case study is an example of an organisational culture which values relationships for sustainability and demonstrates quality participatory practices.

What is the Residents Panel? The Resident's Panel at Parramatta City Council ${ }^{38}$ provides the vehicle for Council to have an ongoing relationship with its community. People on the Residents Panel have their say on matters that relate to a wide variety of areas, such as the environment, social Issues, economic Issues, housing Issues, Council services and the future direction for the City of Parramatta.

Panel members are involved in:

- Completing Surveys - using mail, phone and also email based

- Attending Focus groups - in person or online

- Being involved in In-depth interviews

- $\quad$ Attending public meetings and workshops.

Currently there are over 2,000 people on the Panel. Each has nominated areas of interest and is contacted by Council regularly. Additional panel members are being sought constantly and at each consultation, panelists are invited to bring family, friends and neighbours with them. As far as Panel membership is concerned no distinction is made between property owners and renters.

These relationships are not just built on a project-by-project basis, but are fostered over time through the creation of, and participation in, the Residents Panel. Members of the Residents Panel are involved in every important consultation that Council conducts. Their input helps Council in its understanding of community issues and how Council might approach these.

Why does this particular relationship work? This way of building relationships works because it is built on the needs and interests of the community and is strongly supported by Council. Each consultation is delivered through the Residents Panel so that there is certainty of ongoing contact. Panel members are given the opportunity to provide input and gain feedback about what has happened to that input. People on the Panel can also opt in and opt out, as they wish, from a specific consultation process.

Members of the Resident's Panel are also provided with necessary information for consultations. For example, a consultation on the future outlook and design of the CBD may require maps, drawings and visuals to be supplied to members so that can express their view.

One of the authors of this article recently worked with Council on a major consultation for the development of a sustainability plan. All consultation occurred though focus groups of Panel members. Members of the community were well informed and their level of contribution was of high value. Panel participants can see that their ideas have been implemented; for example the Parramatta CBD Loop Bus (a free bus service provided around the Parramatta CBD) came from a Panel meeting. One challenge for Parramatta City Council is in gaining sufficient young Panel members.

What helps the Panel process work? Through the Panel, Council is able to better understand the needs and aspirations of the community and involve members of the community in decision making processes. It also helps to increase transparency and accountability in decision making and build capacity in local residents to affect Council decisions.

Contact details: Community Relations Unit, Parramatta City Council, NSW Australia

\footnotetext{
${ }^{38}$ www.parramatta.nsw.gov.au
} 


\section{Case Study 2: Wollongong, Shellharbour and Kiama Councils - Sustainable Illawarra}

This case study demonstrates both intra-institutional relationship arrangements for sustainability and how building of relationships with community participants during the development of the project ensures that the project meets the needs of community stakeholders.

What was Sustainable Illawarra? ${ }^{39}$ Sustainable Illawarra was a joint sustainability initiative involving Wollongong, Shellharbour and Kiama Councils, with support from the NSW Government's Environmental Trust. The project involved three separate project components - stormwater reuse projects, institutional change and community sustainability education. The project was implemented over three years from August 2007-2010. Relationship building was at the heart of the programme and this case study focuses on the community education component of the project.

What relationships were built? The framework for the three Councils working together to deliver the Sustainable Illawarra project was created via a Memorandum of Understanding. Wollongong City Council was identified as the lead Council and the Sustainable Illawarra Project Manager and project officers operated from this location. Delivery of the project was overseen by a steering committee of senior managers from the three Councils, and provided direction and approval processes. To draw on the expertise of environment officers from across the three Councils, working parties were established to develop and implement the Sustainability Begins at Home community education component of the project. Council staff joined one of four working parties (biodiversity, water and energy, waste and better buying, and sustainable food) and each met on a monthly/bi-monthly basis. Over the course of the project over 30 staff from the Councils' environment teams were involved in the design and delivery of the community sustainability education initiatives. This required substantial collaboration and highly positive relationship building and maintenance skills. The community was engaged in the development stages of the project primarily via a community survey undertaken with 900 residents. The programme was varied throughout in response to community feedback and workshop evaluations.

The project engaged 9,355 residents (3.3\% of the 283,000 population) through the 124 Sustainable Illawarra workshops, walks, tours and major events. It supported workshop participants to share the skills and knowledge they gained at Sustainable Illawarra workshops with an average of seven others, expanding the influence to 73,580 residents (26\% of the regional population). Seventy six percent of workshop participants identified that the workshop significantly increased their knowledge and confidence. All surveyed workshop participants identified positive changes they had undertaken at home.

Why did the relationships work? There was a very strong commitment from all staff involved in this project to maximise the opportunity to create and deliver quality sustainability education initiatives to the community. Regular communication was critical to building working relationships and also a challenging aspect of the project delivery, with multiple staff from three different Councils involved.

Following the completion of Sustainable Illawarra, Council staff members continue to draw upon the relationships built through the project. As an example, the three Councils are working together to implement a Ride to Work Week initiative, and are utilising tried and tested promotional strategies to engage the community in this event. The project final evaluation report provides much more detail into the relationships built, activities undertaken and recommendations from the Sustainable Illawarra team.

Contact details: Alison Mellor, former Project Manager Sustainable Illawarra, NSW Australia, can now be contacted at Shellharbour Council.

\footnotetext{
${ }^{39}$ All data drawn from the Sustainable Illawarra Final Evaluation Report which can be obtained from the Local Government and Shires Association Website at www.lgsaplus.net.au/resources/documents/Sustainable_Illawarra_Final_Report_September_2010.pdf
} 


\section{Case Study 3: Relationships in a region - Wellington, Blayney, Cabonne and Central Tablelands Water Strategic Alliance (the WBC Alliance)}

This case study demonstrates intra-institutional arrangements for sustainability outcomes, Councils recognising the importance of relationship management and the benefit $s$ that flow from a project manager who sees relationship management as a core aspect of her role.

Why does this particular relationship work? This alliance, formed in 2003, comprises three regional Councils and a water authority in the western part of New South Wales who over the past three years have benefitted from a dedicated staff member. ${ }^{40}$ Leadership is critical to the success of the WBC Alliance. It is demonstrated by a common agreement between the Mayors, Deputy Mayors and General Managers as to its purpose, goals and the resources they put into it. Working on and in the Alliance, and the benefits it brings, is part of the regular activities within and between the Councils. The lynchpin of its success is the investment that the Executive Team made in bringing in an Executive Manager for the Alliance. Her focus has been relationship management. She has extended the Alliance from agreements between the Executive Team to all levels of Council being involved in developing and coordinating advisory and working groups. The Executive Manager has respect from the members, has credibility, is cooperative and is enthusiastic about the Alliance itself. She sees relationship management as an essential skill to support those she works for and with.

The Executive Manager uses a combination of relationship management and a project management approach to the collaborative work they do, setting realistic timelines and clear responsibilities and outcomes. This avoids false expectations and wasting time. The Alliance also has a clear operating structure running across all the member organisations and across all staffing levels with the different Councils.

What benefits does this relationship model bring about? While the Alliance was originally formed as an alternative model to amalgamation, it now demonstrates benefits across all aspects of Council responsibilities. Activities span from developing a mutual sustainability charter to managing climate change and gaining funding for regional environmental works, through to efficiency gains, demonstrating financial savings and increasing skills and knowledge across the professions (including in asset management), Development Application processing, GIS systems and conducting internal audits). The Alliance is a positive example of sharing knowledge and experiences within local government.

What makes it work? Accountability within, and for the Alliance, is embedded into the contracts for General Managers. Accountability and performance measures on collaboration are included the position descriptions of Senior Management. Demonstrating the high value put on collaborative approaches through the Alliance, one Council has even extended responsibility for collaboration into all staff position descriptions. The lynchpin for all the networks in the Alliance; the advisory group, professional teams and executive, is the Alliance Executive Manager. She, in turn has put in place clear yet simple governance arrangements to ensure that all parties are involved and kept up to date with their Alliance work and its outcomes. This Alliance is a positive example of acknowledging the importance of relationship and systems management to reap rewards.

Contact details: http://wbcalliance.nsw.gov.au or contact Donna Galvin at the WBC Alliance, NSW Australia

\footnotetext{
${ }^{40}$ This case study was prepared after telephone interview with Executive Manager and author's personal experience of the WBC Alliance
} 
These case studies demonstrate that relationship building requires focus, time, energy, listening and a commitment to ongoing conversations. It is essential to achieving the extent of change we are seeking in society. It is vital and it reaps rewards. All of the case studies demonstrate different approaches to the process, but each is underpinned by the recognition that relationships can make or break the success both at the time of delivery and into the future.

Each of these case studies indicates willingness by Councils to listen and vary an approach and/or a programme based on what is heard. These Councils recognise and respect the knowledge that community members and businesses have and bring to the table. Without this acknowledgement, people engaged in the relating process lose faith and energy. These case studies show what can be achieved when Councils have listened and learnt.

The effort taken to build relationships is demonstrated in these case studies. The sum of the outputs is greater that the amount of input required; programmes have integrity and are more easily sustained into the future. Credibility can be increased and, importantly for capacitybuilding programmes, maintained into the future.

Relationship-building requires a champion or two (Taylor 2009). Although not explicitly detailed in the actual descriptions of the case studies above, each project had a driver and it was that person and their team (in some cases) that built the relationships required to make the programme work. Often too, they were the champion of the process within their Council. They brought people along with them, showed the benefits, fought the battles and reported on the gains, because they saw the value of building and managing relationships for sustainability.

\section{Techniques and approaches to fostering healthy relationships in work}

Clearly there are a range of changes that can be made to better value and improve relationship management in our work. In the previous sections we described these and we note that they are broadly encompassed within the following scope:

- Incorporating relationship management for sustainability into inter-institutional arrangements such as between different levels of government or groups of Councils working in collaboration.

- Developing, valuing and managing relationships within an organisational culture. For example, such a culture includes the roles of leaders in modelling the value placed on relationship management. 
- Supporting project managers to specifically identify, develop and manage relationships directed towards sustainability outcomes.

- Promote the role and responsibility we all have as individuals participating in programmes to work on relationships. For example this includes facilitating changes in communication processes that are used.

It is best when all those involved in sustainability initiatives share a commitment to using techniques and learning skills required to build and maintain ongoing relationships.

Managing sustainability initiatives sometimes requires expertise in negotiation and conflict resolution; skills in assertiveness and active listening are of real value (see for example Barnlund, 2008, Berko, Wolvin and Wolvin, 2010). Even when there is no conflict or markedly different values, views or working styles, building rapport is essential to establishing and maintaining relationships. Relationships are enhanced through nonjudgemental communication; that is, active listening and the temporary suspension of judgement, so that quality communication can occur. Strategies for building good rapport can be as simple as attending to basic conventions of good communication: using a person's preferred name when speaking with them, listening carefully and actively, explaining words and expressions that may be unfamiliar, not using jargon, explaining what you already know, explaining clearly any specific position you may have, and summing up the discussion when appropriate (Kabatznick and Cullen, 2004).

Within this Section we present some suggestions and approaches for how the sector can better attend to relationships in work, across these four broad spheres. This is not a comprehensive list of guidelines, because that is beyond the scope of our focus, but they should be seen as tips for integrating a higher priority for relationship building and maintenance, within our work (Appelbaum 2005). 
Building significant relationships between organisations at all levels is an important factor in project success. Through inter- institutional arrangements we can:

$\checkmark$ Ensure resources are adequate for the establishment of relationships and agreed understandings of the project processes and goals. Develop planning frameworks, funding applications and/or reporting frameworks that include KPIs related to relationships.

$\checkmark \quad$ Establish formal committees (for example Project Steering Committees) with agreed terms of reference, so each member is clear about the relationship roles, responsibilities and working parameters of the committee. Encourage the establishment of smaller working groups so that people get to work together on specific tasks.

$\checkmark \quad$ Allow time in the early meetings for all participants to get to know each other. Extend the opportunity for relationship building at each meeting, both through formal meeting processes - for example sufficient discussion time - and through informal time - morning tea/lunch etc. Encourage quieter members of the group to speak and manage the group so it is not dominated by one or two voices.

$\checkmark \quad$ Validate and support the relationships that are built though the committee and its processes. Ensure that all key stakeholders are engaged within each project and initiative, and consider formalising relationships through MOUs or letters of agreements as required.

$\checkmark$ Build in a process that ensures that any relationship issues/conflicts that emerge can be discussed and resolved quickly and effectively.

Through changing organisational culture to support the time and energy invested in creating relationships with the community and stakeholders we can:

$\checkmark$ For grant-funded roles, work hard as host Council(s) to welcome the project manager, providing induction into the ways of local government, regular opportunities for personal contact and establishing systems that will raise awareness about the project with key staff, influencers in the community and senior management.

$\checkmark \quad$ Ensure that senior staff and elected representatives within local and state government agencies value and support the time and energy it takes to set-up, manage and extend quality relationships that are focussed on producing ongoing sustainability outcomes.

$\checkmark$ Recognise the challenges in trying to cost relationships and their benefits and acknowledge their yield is more likely to be a long term rather than a shorter term, although poor relations can derail projects. Provide guidance to project officers and/or applicants on the time they might expect to spend building project relationships.

$\checkmark$ Provide training for staff and/or successful recipients on conflict resolution and restorative practices.

$\checkmark \quad$ Include a project relationship dimension in staff performance criteria. Support training for staff on restorative practices and relationship management. Recognise and reward staff achievements in relationship management. 


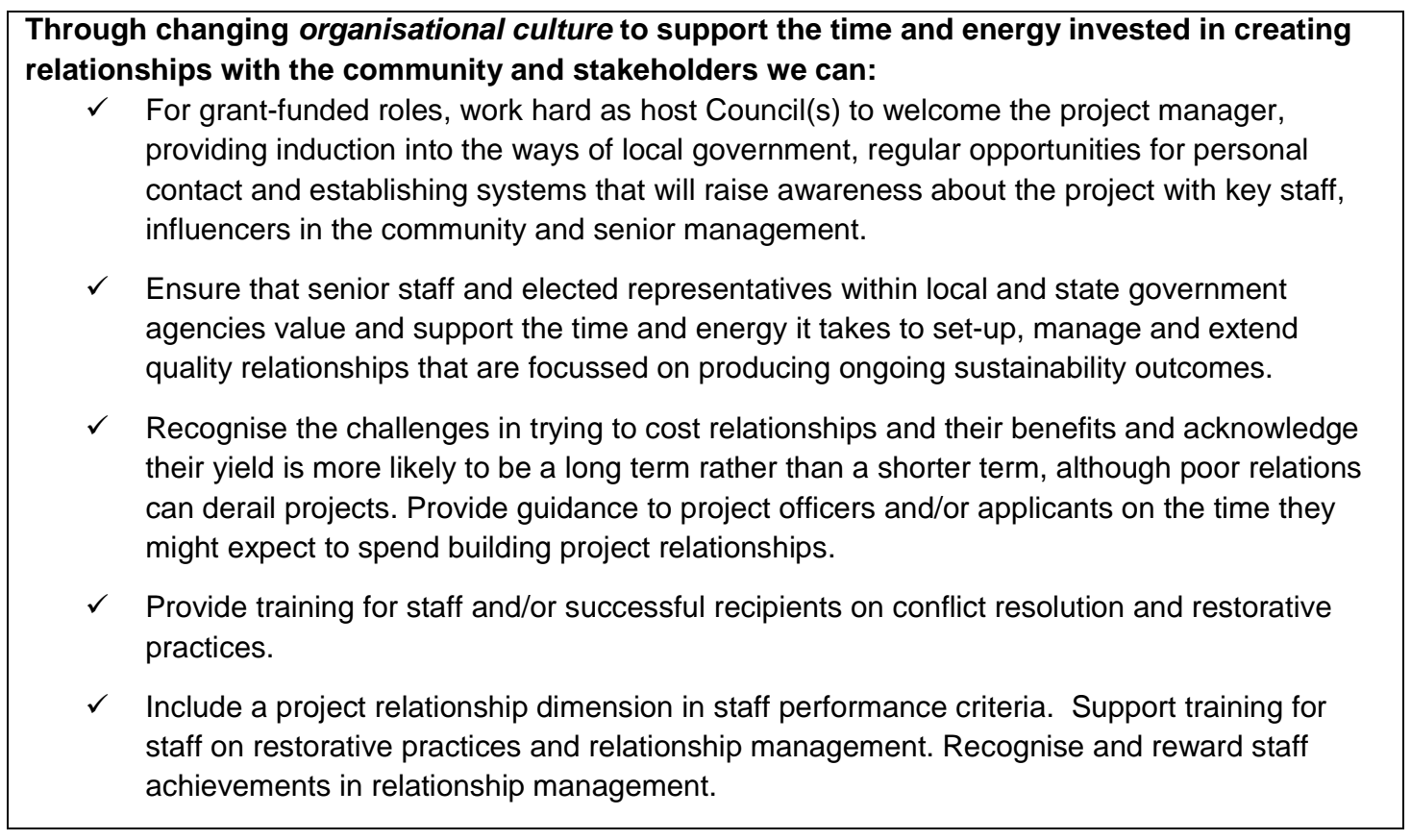

The project manager is crucial in the facilitation of the relationships within all successful sustainability projects. In their role, the project manager can:

$\checkmark \quad$ Ensure the project planning process includes sufficient time at the beginning to build the relationship. This can include discrete tasks such as: stakeholder mapping, initial interviews with stakeholders, consultation on/review of the project brief with stakeholders (DSE, 2005).

$\checkmark$ Get a sense of personal strengths and needs in relationship management. Seek training where necessary.

$\checkmark \quad$ Make a flow chart of relationships early in complex projects. Recognise each one and where they can add value / pose a risk to project outcomes. Be proactive in developing working, professional relationships with others in the project.

$\checkmark$ Appreciate there are real people in this project with needs, feelings, fears, priorities... that are likely to be different to yours. Avoid personal 'put downs' and directing anger aggressively at others. There is no place for these behaviours in constructive, positive relationship building.

$\checkmark$ Develop an evaluation plan at the outset of the project with project stakeholders. Build relational outcomes into the evaluation plan.

$\checkmark \quad$ Clarify roles and responsibilities. Then clarify them again. Keep checking this.

$\checkmark \quad$ Set up agreed communication processes, for all stakeholders even those one or two steps removed from the process. Keep reviewing these - are they still working? Keep lines of communication open.

$\checkmark \quad$ Set up a process for dealing with disagreement. Central is a commitment to working together. Discuss decision making and feedback processes explicitly in the group or relationship. Consider bringing in an independent third person to mediate where relationship breakdown occurs. Identify someone with skills and experience in facilitation or conflict resolution, and experience working in charged emotional situations

$\checkmark$ Be aware that, at times, attitudinal change within organisations is required in order to see the community as partners in a project and work with them to build and maintain the relationships required.

$\checkmark \quad$ Celebrate successes in the project. Recognise and acknowledge good working relations 


\section{All individuals involved in sustainability initiatives can:}

$\checkmark$ Acknowledge early on that all participants have a responsibility for managing interpersonal relationships within that project or programme. Seek to achieve mutually enriching and trusting relationships.

$\checkmark \quad$ Remember that building respectful and trusting relationships is the highest order priority for successful projects. Utilise the skills of active listening, conflict resolution and mediation designed to establish win/win relationships.

$\checkmark$ Recognise that others view the world and projects differently. Try to appreciate these different perspectives, attitudes and values in your own actions and planning. Discuss the similarities and differences with stakeholders. Make an effort to hear and understand the views of others. This requires active listening and a respectful attitude to their views; the more removed their views are from yours, the harder you have to work at understanding what motivates them. Listen hard and then look for common ground and work from that point forward.

$\checkmark \quad$ Avoid taking a 'not speaking' position - there is no time for playing 'no speaks' if relationships are to be built. Whatever happens, it is essential that communication continues to occur. If your views are not yet formed and you need more time to respond, then say that, rather than staying silent which may be construed as negativity.

$\checkmark$ Consider that when views are oppositional, often a graduated response is required. This means that in the early stages of communication about an issue, rather than each side stating strong positions from the outset, there is an attempt made to build rapport and understanding. Spend time identifying 'like rather than difference' and making contact as people rather than about the issue. Move from this point to gaining a better understanding of what underpins individual views and then onto more in-depth statements of the views themselves.

$\checkmark$ Acknowledge that rational argument does not always win the day. Not surprisingly in many conflict situations, both sides believe their argument is rational.

$\checkmark \quad$ State your position assertively when necessary: stating your own position rather than negatively attacking their position. Communicate clearly and in non-judgemental ways. Seek to achieve rapport, trust and confidence through and in communication processes. 


\section{Recommendations and Conclusions}

In order to enhance the focus on relationship building in sustainability initiatives, we recommend that:

1. Funding bodies value and support the time it takes to set up, manage and extend quality relationships focussed on producing ongoing sustainability outcomes. For example, this can occur through funding application and reporting frameworks (such as adding Key Performance Indicators related to relationships), giving guidance on the time applicants might expect to spend building project relationships, providing training to successful recipients on negotiation and conflict resolution skills.

2. Senior staff and elected representatives within local and state government agencies also value and support the time it takes to set up, manage and extend quality relationships that are focussed on producing ongoing sustainability outcomes. They can demonstrate this to staff by adding this dimension of programme delivery to staff KPIs (performance criteria), through induction training and ongoing professional development, and through including it in project planning.

3. As a part of effective planning, project and programme managers take time to map, identify and facilitate the crucial relationships required for the success of their projects.

4. Organisations demonstrate respect for and recognition of the knowledge, skills and contribution that stakeholders bring to Council-led sustainability projects and that this is required during planning, rollout and evaluation phases.

5. All participants in a sustainability programme or project have shared responsibility to work on interpersonal relationships within that project or programme. Project managers or co-ordinators need to take an active role in facilitating this process.

6. Skills in developing and maintaining relationships be recognised as a core component of professional development and personal reflection.

7. Recognise that our different value sets or perspectives can create disagreement or conflict, and that we must work with them respectfully to bring about sustainability outcomes. 
In conclusion then, we contend that relationship management is a pivotal, yet frequently undervalued, variable in the progress and processes of sustainability programmes. We believe that developing and maintaining resilient relationships is a critical foundation for project success.

In highlighting relationships, we have also identified some approaches and case studies that might help both to raise the profile of the importance of relationship-building and relationship-maintenance. We hope that, by highlighting these firmly in the context of sustainability outcomes, we have encouraged some thinking about the emphasis given to interpersonal matters in project design, delivery and evaluation. We believe specific attention to these aspects is vital for those working in our sector.

While this paper has outlined an assortment of ideas for approaching and improving relationships in our work, it is by no means comprehensive, nor intended as a definitive 'solution' to the issue. Instead, we invite practitioners, managers, funding bodies and members of the community to consider how they might better attend to and value relationships in their project work.

\section{Acknowledgements}

The authors would like to thank the project staff who contributed reflections to develop the case studies, and to peers and colleagues who are also interested in effective collaboration through successful relationships.

\section{References}

Abram, D 1997, The spell of the sensuous, Random House, New York.

Appelbaum, Steven H., Steed, Anthony J. (2005) 'The critical success factors in the client-consulting relationship’ Journal of Management Development Volume: 24, Issue 1.

Barnlund, D. C. 2008, 'A transactional model of communication' Communication Theory 2nd edn pp. 47-57.

Berko, Roy M, Andrew Wolvin \& Darlyn Wolvin, 2010, Communicating: A social, career and cultural focus 11th edn, Pearson Education, Boston MA.

Berry, Father Thomas 1998 The dream of the earth, Sierra Club.

Brown V. et al, 2004, Sustainability and health. Allen \& Unwin.

Capra, Fritijof 1982, The turning point Simon \& Schuster, New York.

City of Norwood, Payneham and StPeters, 2012, Sustainability and Quadruple Bottom Line Retrieved (20/05/12) from http://www.npsp.sa.gov.au/page.aspx?u=1608 last updated May 2012.

Cox, Eva (1995) Measuring Social Capital, Extract of Boyer lecture. Retrieved 10/10/10 from http://www.mapl.com.au/A2.htm\#1.\%20What\%20is\%20Social\%20Capital

de Souza Briggs, Xavier 2003, Encyclopedia of community, SAGE Publications.

DSE, See Victorian Government Department of Sustainability and Environment

HCCREMS, 2008, The guide to good governance and ecologically sustainable development for local councillors. Hunter, Central Coast Regional Environmental Management Strategy. 
Jigsaw Services, 2004, Triple Bottom Line Reporting for Local Government. Prepared for Adelaide Hills Council, Alexandrina Council and the City of Salisbury. http://www.lga.sa.gov.au/webdata/resources/files/Triple_Bottom_Line_Reporting_for_Local_ Government__Final_Report_pdf1.pdf

Kabatznick R. and M. Cullen 2004 'The travelling peacemaker: a conversation with Marshall Rosenberg' Inquiring Mind, Fall issue.

Liverpool City Council (no date) Our vision for the environment. Retrieved (20/05/12) from http://www.liverpool.nsw.gov.au/sustainability.htm

NSW Division of Local Government 2009 Planning a Sustainable Future: Planning and Reporting Guidelines for Local Government in NSW. Retrieved (10/10/10) from www.dlg.nsw.gov.au

NSW Division of Local Government (2009) Local Government Integrated Planning and Reporting Framework: Frequently Asked Questions and Their Answers. Retrieved (10/10/10) from www.dlg.nsw.gov.au

Parramatta City Council (no date) Retrieved (10/10/10) from http://www.parracity.nsw.gov.au/

Queensland Government Department of Infrastructure and Planning 2008 Toolbox 12, Reference Quadruple Bottom Line. Retrieved (22/10/10) from http://www.dip.qld.gov.au/docs/planning/corporate/publications/local_govt/plan_and_deliver/t oolbox_12_reference.pdf

Rogers C.R, 1970, Carl Rogers on encounter groups, Harpers \& Row, New York.

Sustainable Illawarra, 2010, Final Evaluation Report. Available at: Local Government and Shires Association Website at www.lgsaplus.net.au/resources/documents/Sustainable_Illawarra_Final_Report_September_2010.pdf

Taylor, A. 2010. Sustainable urban water management: The champion phenomenon. PhD Thesis. National Urban Water Governance Programme, Monash University, Victoria, Melbourne.

Victorian Government Department of Sustainability and Environment, 2005, Effective Relationships. Building engagement with community and other stakeholders.

Watts, Alan 2005, The Way of Zen, Macmillan Audio.

Wild S, (2006) The role of local government in environmental and heritage management. Paper prepared for the 2006 Australian State of the Environment Committee, 2006. Retrieved (10/10/10) from http://www.environment.gov.au/soe/2006/publications/integrative/localgovernment/introduction.html 